University of Wollongong

Research Online

Faculty of Engineering and Information

Faculty of Engineering and Information

Sciences - Papers: Part A

Sciences

$1-1-2016$

Facilitating student and staff engagement across multiple offshore campuses for transnational education using an immersive video augmented learning platform

Sasha Nikolic

University of Wollongong, sasha@uow.edu.au

Wanqing Li

University of Wollongong, wanqing@uow.edu.au

Follow this and additional works at: https://ro.uow.edu.au/eispapers

Part of the Engineering Commons, and the Science and Technology Studies Commons

Research Online is the open access institutional repository for the University of Wollongong. For further information contact the UOW Library: research-pubs@uow.edu.au 


\title{
Facilitating student and staff engagement across multiple offshore campuses for transnational education using an immersive video augmented learning platform
}

\begin{abstract}
Opportunities in transnational education have been growing across the higher education sector. The incentive for institutions to explore opening offshore satellite campuses includes access to more students and building the institutions reputation across the globe. A number of risks are also associated with transnational education, especially in terms of quality. It is important that students across all campuses receive the same high standard of education. That is, students at offshore campuses should not be placed at a disadvantage compared to students studying at the institutions main campus. This paper explores the possibility of providing students from offshore campuses better access to teaching staff from the institutions main campus. An immersive video augmented platform called iSee is used to simultaneously connect students from Singapore and Malaysia with teaching staff in Wollongong. The students undertook an exam revision session using video avatars in a virtual lecture theatre. The pilot showcased the opportunities of implementing this technology to improve student engagement and reduce academic workload. It also reinforced the need for more research in the transnational education field to ensure the same graduate outcomes are being achieved across campuses.
\end{abstract}

\section{Keywords}

education, transnational, campuses, offshore, multiple, across, engagement, staff, student, facilitating, platform, augmented, learning, video, immersive

\section{Disciplines}

Engineering | Science and Technology Studies

\section{Publication Details}

S. Nikolic \& W. Li, "Facilitating student and staff engagement across multiple offshore campuses for transnational education using an immersive video augmented learning platform," in IEEE International Conference on Teaching, Assessment and Learning for Engineering (TALE), 2016, pp. 1-5. 


\section{Facilitating Student and Staff Engagement Across Multiple Offshore Campuses for Transnational Education Using an Immersive Video Augmented Learning Platform}

\author{
Sasha Nikolic \\ Engineering and Information Sciences \\ University of Wollongong \\ Wollongong, NSW, Australia \\ sasha@uow.edu.au
}

\author{
Wanqing Li \\ Engineering and Information Sciences \\ University of Wollongong \\ Wollongong, NSW, Australia \\ wanqing@uow.edu.au
}

\begin{abstract}
Opportunities in transnational education have been growing across the higher education sector. The incentive for institutions to explore opening offshore satellite campuses includes access to more students and building the institutions reputation across the globe. A number of risks are also associated with transnational education, especially in terms of quality. It is important that students across all campuses receive the same high standard of education. That is, students at offshore campuses should not be placed at a disadvantage compared to students studying at the institutions main campus. This paper explores the possibility of providing students from offshore campuses better access to teaching staff from the institutions main campus. An immersive video augmented platform called iSee is used to simultaneously connect students from Singapore and Malaysia with teaching staff in Wollongong. The students undertook an exam revision session using video avatars in a virtual lecture theatre. The pilot showcased the opportunities of implementing this technology to improve student engagement and reduce academic workload. It also reinforced the need for more research in the transnational education field to ensure the same graduate outcomes are being achieved across campuses.
\end{abstract}

Keywords - augmented video, iSee, student collaboration, quality, transnational education.

\section{INTRODUCTION}

Transnational education (TNE) involves the delivery of a program of study in a different country to the one where it was developed and awarded, with such programs attracting in excess of 70,000 international students from Australian universities alone [1]. The global demand for quality higher education has seen predictions that transnational education will reach 7.2 million students by 2025 [2]. Running programs of study across international borders can be very challenging and is associated with a number of risks and rewards. The lure for institutions to setup transnational campuses include new sources of revenue together with increasing the universities profile and reputation [1]. The incentive for students to enroll in transnational programs are generally based on greater employment prospects with students gaining a perceived better international outlook and multicultural experience compared to local non-TNE students [3, 4]

Transnational education is not a risk free business opportunity for universities. For example, they need to deal with cultural, government, enrolment, establishment and operation risks [5, 6]. Additionally, universities need to consider how quality will be controlled with the satellite campus being located at a distance from the main campus. A quality learning experience is important to student learning and the reputation of the university [7, 8]. In particular, questions have been raised in who is teaching at the offshore campuses and if value is being obtained by offshore students if the teaching staff are not directly from the university offering the degree [9]. Two approaches used in transnational education include using local staff with the main campus staff mainly undertaking a moderation role to ensure quality; and intensive classes where faculty come to the campus and deliver all the content in one or two weeks [1]. The rapid pace of learning associated with intensive delivery can result in a decrease in the effectiveness of learning. As a result, learning must be compensated with additional mechanisms, such as more tutorials and laboratories at a normal pace. However, it cannot be fully compensated. Running intensive classes in burst mode, together with the burden of travel can significantly impact the workload and stress levels of teaching staff and students involved in transnational education

The purpose of this pilot study is to investigate if technology can be used to ensure quality in transnational programs by providing offshore students greater access to teaching staff from the main campus by removing the burden of travel. In particular, this is often faculty who originally designed and developed the subject materials. Technology could assist in a number of ways:

a) As a new mechanism to compensate the deficiency of intensive delivery, e.g. main campus faculty to run a few tutorials/lab/review sessions, provide weekly or fortnightly consultations 
b) Deliver subject remotely with more hours in an intensive mode + a)

c) Deliver the subject remotely in a normal pace with tutorials/labs running locally

d) Staff of the main campus to deliver the lectures and run the tutorials, labs and consultations remotely.

Moving down the list from a) to d), the requirements (e.g. environment, interactions) placed upon the available technologies increases. Therefore, this pilot study is targeted at the simplest implementation. This paper commences by investigating possible technologies and discussing why an immersive video augmented virtual world technology called iSee was chosen for this pilot. The software is used by an associate professor at the University of Wollongong to provide an exam revision session to students in Singapore and Malaysia undertaking the same third year Multimedia Computing course.

\section{TECHNOLOGIES}

Video based technologies have been shown to be very beneficial for learning $[10,11]$. In terms of online collaboration popular 2D products include Adobe Connect, Google Hangouts and Skype; and 3D products include Second Life (non-video based) and iSee (video based)[12]. Additionally, a number of trials have investigated synchronously blending remote and face-to-face students to increase student engagement and co-presence [13, 14]. When using video, 2D products have limited scalability with the number of simultaneous users, generally fewer than ten [15]. Second Life a non-video based 3D technology removes the technological issues surrounding scalability. Substantial literature has outlined how this scalable technology can be used to increase engagement of students and staff across multiple campuses [16-19] and be used to assess learning [20, 21]. The limitation of Second Life is that the exclusion of a video avatar means that facial expression and body language are excluded from communication, limiting the experience [12]. This limitation is removed using iSee, using video avatars allowing students to gather and communicate in a natural orientation [22]. This is achieved through video augmentation, which is creating new learning opportunities [23-27]. The software has been used to connect students with industry to improve project based learning [28] and to provide students with an insight to career opportunities by connecting them to alumni from around the world [29]. Due to the scalability and benefits of video avatars this technology was chosen for the pilot case study. A license to use iSee was purchased using grant funding. This allowed students and staff to download, install and use the program.

\section{DESIGN}

A third year Multimedia Computing course was used for this case study. This course is a core requirement for the major Multimedia and Game Development of a Bachelor of
Computer Science at the University of Wollongong. The course is taught at the Wollongong Campus as well as UOW's offshore campuses at the Singapore Institute of Management (SIM), and the INTI International College Malaysia. The Wollongong staff that designed and developed the subject play a role in teaching the content at SIM but only play a moderation role at INTI. The teaching schedules across the two campuses were slightly different with enough overlap towards the end of the schedule to run the joint exam revision session using iSee.

A total of 18 students were enrolled in the course at SIM, with another 18 students enrolled at INTI. The Wollongong lecturer advertised the voluntary exam revision session two weeks before the event and provided students with a pre-event survey to gain an understanding of their motivation and perceptions of participating in such a virtual event. A follow up survey was provided to students after the event to detect changes in perception and to evaluate the experience. The iSee platform provides the following functionality:

Movement: Each user is represented by a video avatar controlled with the keyboard and mouse. The avatar can move freely throughout the virtual world in a first person view. Users can also select to change the view to third person to enable seeing their own avatar. Users will move towards other avatars to join discussions, move around the virtual world to explore the design, or move towards boards to interact with learning tools.

Boards: Boards are used within iSee for the sharing of information and for collaborative work. Users can upload images and presentations; use writing and drawing tools; share their screen or applications with other participants; and work on multiple choice quizzes. Users can snap a board to full or partial screen to gain a closer look at content. Presentations can be viewed in sync mode (changes such as moving through slides are seen by all users) or without sync (changes are not replicated to all users).

A virtual world replicating a lecture theatre was used. The lecturer was provided with two boards to display content. One board was used to display learning material and the second was used to display sample exam questions for the students to work on as is seen in Figure 01. The students could snap the contents of any board to their screen at any time to observe the material closely as is seen in Figure 02. If a student removed the synchronization with the board they could move forward and backwards through the presentation slides independently. The lecturer when presenting can change his microphone to a megaphone setting. This enables his voice to propagate equally across the virtual room, instead of the default spatial audio where participants only hear people in close range (as expected with natural conversation). As seen in Figure 01 the megaphone feature was setup to display two extra enlarged video feeds of the lecturer. This enabled his face and body language to be seen by the students at all times irrespective of where he was facing or talking to. This is especially important when the lecturer would need to face the board to shine a laser pointer to content on the board. 


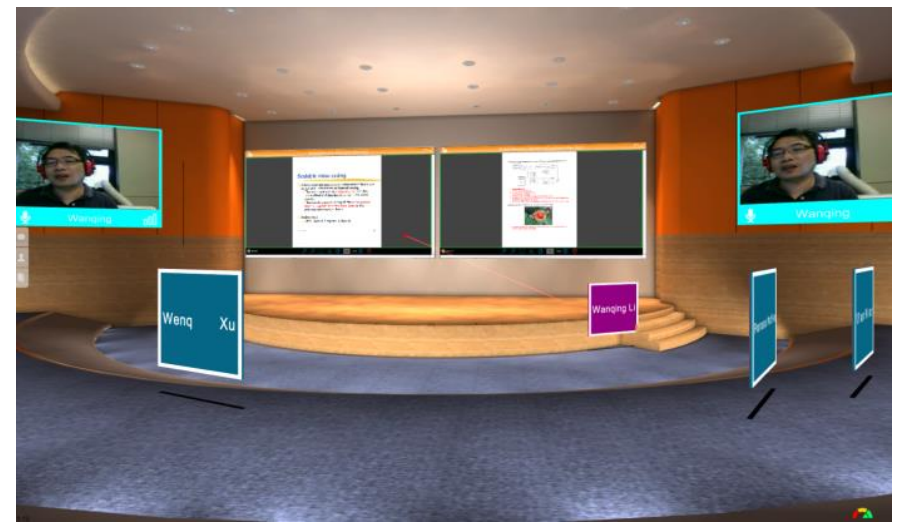

Figure 1: The lecture theatre map designed for the case study

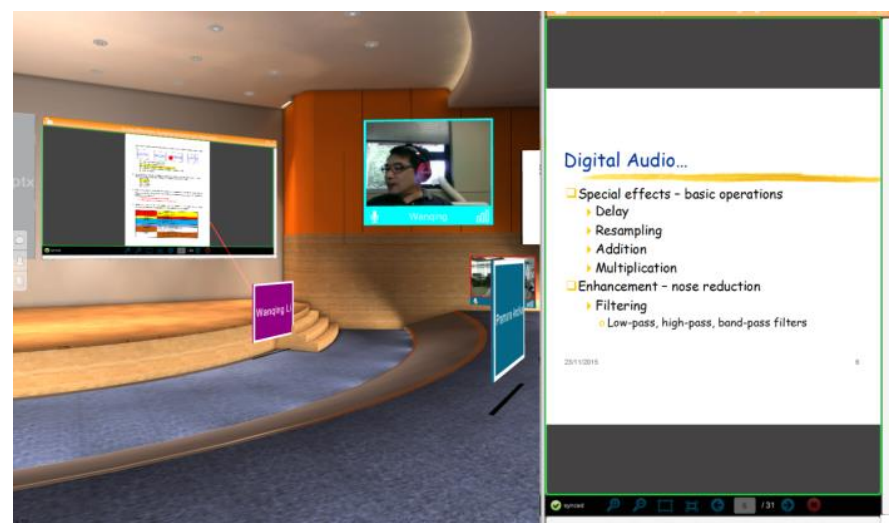

Figure 2: An example of using the white board snap feature

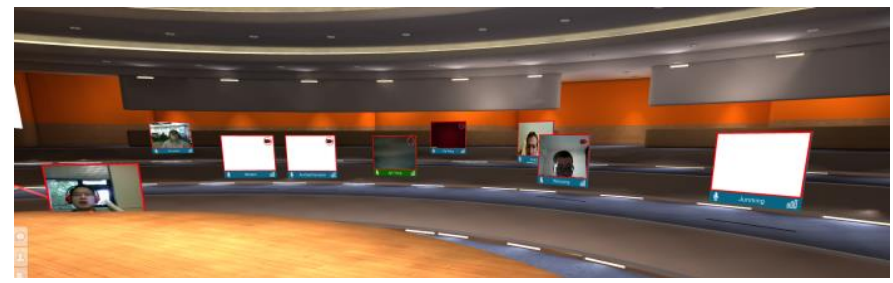

Figure 3: All student participants had disabled or paused the webcam of their avatar

\section{RESULTS AND DISCUSSION}

A total of seven students participated in the event with six students from SIM (33\%) and only one from INTI (5\%). Only three students completed the pre and post surveys providing little insight into the activity. Due to the low sample the quantitative data was insufficient to satisfactorily provide meaning to the qualitative data.

Particularly concerning was that only one INTI student participated. There are two possible reasons for the very low participation rate. The first is that the event was scheduled at 9:30am during the recess week, before exams commence. Scheduling the activity during this non-teaching week could have been a disincentive for students to participate. The second possible reason could have been that the Wollongong lecturer teaches directly to the students at SIM and not at INTI, and therefore the promotion of the activity may not have been as influential. However, from experience in running exam revision sessions at Wollongong, the authors' expectation was to have seen a participation rate of at least fifty percent.

The most interesting observation of the event was that all the students disabled or paused their webcam as is seen in Figure 3. This meant that the key advantage of using iSee compared to other platforms such as Second Life was neutralized as participants could not see each other's faces and body language. The only active video avatar was that of the lecturer. This was in stark contrast to previous iSee case studies run with students from Wollongong and Dubai campuses in which the students embraced and appreciated the video avatar. Literature suggested that this is due to the culture of protecting ones face deeply rooted in most Asian cultures [30]. This in part was backed by the two students that answered the post event survey question 'Did you enable your webcam during the event?' One of the students stated that they were 'uncomfortable with using a webcam' and the other stating 'privacy'. This suggests substantial education and incentive may be needed to encourage the web cams to be enabled.

The delivery of the virtual lecture played out in a similar structure as would be expected in a traditional physical lecture. The lecturer discussed concepts displayed from PowerPoint slides and this was broken up with problems for the students to answer to confirm understanding. However, the students failed to interact. The many questions posed by the lecturer were returned with silence. Only on one occasion the lecturer received a text based response. As the students had disabled their video the lecturer could not see the students faces to gage whether the students did not understand the concepts or that they were simply not at their computer. The plan was to commence the case study with an interactive activity for the students to get to know each other and explore the functionality of the iSee software. Unfortunately, this was missed and may have contributed to the lack of contribution from the students. However, this lack of contribution is also noticed by many Asian students within physical lectures at the Wollongong campus and SIM. It is very difficult to get the students involved in active discussions. Incentives, targeted activities and encouragement are generally ways teaching staff try and increase student engagement. It could be that lecture styled activities in iSee may not be the most effective way of engaging with Asian students. Tutorials or other interactive activities such as student pitches [28] possible with iSee, may be more effective.

A key goal of this study was to explore the feasibility of using this technology in a transnational setting. All participants managed to download, install and use the technology with no reported problems. Video and audio communication worked, allowing participants from all three campuses to replicate a physical lecture experience. Therefore, in terms of the technology iSee is a feasible product for supporting transnational education. 
In terms of learning, further research is needed to understand and implement effective pedagogy required to support students located at Asian offshore campuses using iSee. The findings support the expansion of this study beyond the pilot stage using student volunteers that provided limited data.

\section{CONCLUSION}

This study investigated using an immersive video augmented learning platform called iSee to effortlessly bring together students studying at offshore campuses in Singapore and Malaysia with teaching staff located in Wollongong. The study attempted to determine if the technology could be used to replace some of the travel required by teaching staff from the universities main campus. This in turn would lead to increased opportunity for students and staff across campuses to engage. Therefore, the results of this study are beneficial to teaching staff involved in transnational education exploring ways to improve the student experience and quality.

The technology worked as expected and provided the authors with confidence in using iSee in a transnational setting. Unfortunately, this study was unable to collect substantial quantitative data due to the small sample. However, the ethnographic component highlighted the importance of the attempt to use iSee and the need for the authors to expand the study to investigate effective pedagogy.

With the students at all three campuses entitled to a UOW degree at completion, it is important that the learning objectives and skill attainment is consistent with that required for accreditation as well as both Australian and UOW quality frameworks. In this case study, it is ensuring that students studying in the Asian offshore campuses also develop oral communication competency; have the confidence to express ideas and to have discussions with others; and to develop a global understanding. In part, this involves changing the Asian student experience to ensure greater interactivity between students and staff.

\section{ACKNOWLEDGMENT}

This research was supported by a University of Wollongong Educational Strategies Development Fund (ESDF) Grant

\section{REFERENCES}

[1] F. Rizvi, "Offshore Australian higher education," International Higher Education, vol. 37, pp. 7-9, 2004.

[2] D. G. Waterval, J. M. Frambach, E. W. Driessen, and A. J. Scherpbier, "Copy but not paste a literature review of crossborder curriculum partnerships," Journal of Studies in International Education, vol. 19, pp. 65-85, 2015.

[3] J. Knight and J. McNamara, "The Impact of Transnational Education in Receiving Countries," International Higher Education, pp. 3-5, 2015.
[4] Q. $\mathrm{Gu}$ and M. Schweisfurth, "Transnational connections, competences and identities: experiences of Chinese international students after their return 'home'," British Educational Research Journal, 2015.

[5] G. McBurnie, "International Branch Campuses: Australian Case Studies," International Higher Education, 2015.

[6] B. J. Bannier, "Global Trends in Transnational Education," International Journal of Information and Education Technology, vol. 6, pp. 80-84, Jan 2016 2016.

[7] S. Nikolic, P. J. Vial, M. Ros, D. Stirling, and C. Ritz, "Improving the Laboratory Learning Experience: A Process to Train \& Manage Teaching Assistants," IEEE Transactions on Education, vol. 58, pp. 130-139, 2015.

[8] S. Nikolic, C. Ritz, P. J. Vial, M. Ros, and D. Stirling, "Decoding Student Satisfaction: How to Manage and Improve the Laboratory Experience," IEEE Transactions on Education, vol. 58, pp. 151158, 2015.

[9] P. Altbach, "Twinning and branch campuses: The professorial obstacle," International Higher Education, pp. 2-3, 2015.

[10] S. Nikolic, "Understanding How Students Use and Appreciate Online Resources in the Teaching Laboratory," International Journal of Online Engineering, vol. 11, pp. 8-13, 2015.

[11] P. J. Vial, S. Nikolic, M. Ros, D. Stirling, and P. Doulai, "Using Online and Multimedia Resources to Enhance the Student Learning Experience in a Telecommunications Laboratory within an Australian University," Australasian Journal of Engineering Education, vol. 20, pp. 71-80, 2015.

[12] S. Nikolic, M. J. W. Lee, and P. J. Vial, "2D versus 3D collaborative online spaces for student team meetings: comparing a web conferencing environment and a video-augmented virtual world," presented at the 26th Annual Conference of the Australasian Association for Engineering Education, Geelong, 2015.

[13] M. Bower, M. J. Lee, and B. Dalgarno, "Collaborative learning across physical and virtual worlds: Factors supporting and constraining learners in a blended reality environment," British Journal of Educational Technology, 2016.

[14] M. Bower, J. Kenney, B. Dalgarno, M. J. Lee, and G. E. Kennedy, "Blended synchronous learning: Patterns and principles for simultaneously engaging colocated and distributed learners," in Proceedings of the 30th ASCILITE Conference. Sydney, Australia, 1st-4th December, 2013.

[15] J. C. Tang, C. Wei, and R. Kawal, "Social telepresence bakeoff: Skype group video calling, google+ hangouts, and microsoft avatar kinect," in Proceedings of the ACM 2012 conference on 
Computer Supported Cooperative Work Companion, 2012, pp. 37-40.

[16] Y. Masters and S. Gregory, "Second Life: Harnessing virtual world technology to enhance student engagement and learning," in Proceedings of the University Learning and Teaching Futures Colloquium, 2010.

[17] L. J. Eaton, M. Guerra, S. Corliss, and L. Jarmon, "A statewide university system (16 campuses) creates collaborative learning communities in Second Life," Educational Media International, vol. 48, pp. 43-53, 2011.

[18] I. Branovic, R. Popovic, N. Jovanovic, R. Giorgi, B. Nikolic, and M. Zivkovic, "Integration of simulators in virtual 3D computer science classroom," in Global Engineering Education Conference (EDUCON), 2014 IEEE, 2014, pp. 1164-1167.

[19] S. J. Grant, H. Huang, and S. E. Pasfield-Neofitou, "Language learning in virtual worlds: the role of foreign language and technical anxiety," Journal For Virtual Worlds Research, vol. 6, 2013.

[20] A. Fardinpour, M. M. Pedram, and M. Burkle, "Intelligent Learning Management Systems: Definition, Features and Measurement of Intelligence," International Journal of Distance Education Technologies (IJDET), vol. 12, pp. 19-31, 2014.

[21] A. Fardinpour, T. Reiners, and H. Dreher, "Actionbased learning assessment method (ALAM) in virtual training environments," in 30th Ascilite Conference Proceedings, 2013, p. 267.

[22] iSee Meetings. (12 June 2015). iSee. Available: http://www.isee-meetings.com/

[23] L. Irving and J. Hoffman, "Nyungar Place Stories Pilot: using augmented reality for Indigenous cultural sustainability," in 31st ASCILITE Conference, Dunedin, New Zealand, 2014.
[24] M. Dunleavy, C. Dede, and R. Mitchell, "Affordances and limitations of immersive participatory augmented reality simulations for teaching and learning," Journal of Science Education and Technology, vol. 18, pp. 7-22, 2009.

[25] M. Smith, A. Maiti, A. D. Maxwell, and A. A. Kist, "Augmented and Mixed Reality Features and Tools for Remote Laboratory Experiments," International Journal of Online Engineering (iJOE), vol. 12, pp. 45-52, 2016.

[26] M. Bower, C. Howe, N. McCredie, A. Robinson, and D. Grover, "Augmented Reality in education-cases, places and potentials," Educational Media International, vol. 51, pp. 1-15, 2014.

[27] S. Ternier, R. Klemke, M. Kalz, P. Van Ulzen, and M. Specht, "ARLearn: Augmented Reality Meets Augmented Virtuality," J. UCS, vol. 18, pp. 21432164, 2012.

[28] M. J. W. Lee, S. Nikolic, P. J. Vial, C. Ritz, W. Li, and T. Goldfinch, "Enhancing project-based learning through student and industry engagement in a videoaugmented 3D virtual trade fair," IEEE Transactions on Education, vol. 59, pp. 290 - 298, 2016.

[29] S. Nikolic, M. J. W. Lee, T. Goldfinch, and C. H. Ritz, "Addressing Misconceptions About Engineering Through Student-Industry Interaction in a VideoAugmented 3D Immersive Virtual World," in Frontiers in Education Conference (FIE), 2016, 2016.

[30] F. N. Tazijan, S. Ab Rahim, F. S. A. Halim, A. Abdullah, I. Ismail, and T. A. Cochrane, "Implementing a Virtual Presentation Program in ESLClassrooms," International Journal of $e$ Education, e-Business, e-Management and $e$ Learning, vol. 2, p. 218, 2012. 